\title{
An Unusual Presentation of Celiac Disease: Vertigo
}

\section{Çölyak Hastalığının Nadir Bir Prezentasyonu: Vertigo}

\section{Benan Kasapoğlu', (1) Ahmet Yozgat' ${ }^{2}$, (1) Murat Kekilli}

'Division of Gastroenterology, Department of Internal Medicine, Lokman Hekim University Faculty of Medicine, Ankara, Turkey ${ }^{2}$ Division of Gastroenterology, Department of Internal Medicine, Ufuk University Faculty of Medicine, Ankara, Turkey ${ }^{3}$ Division of Gastroenterology, Department of Internal Medicine, Gazi University Faculty of Medicine, Ankara, Turkey

\begin{abstract}
Celiac disease (CD), intolerance to gluten, is characterized by the autoimmune inflammation of the small intestine in genetically susceptible individuals. Herein, we will report a case of a patient diagnosed with CD during investigations performed for recurrent vertigo attacks. Clinicians should be aware that CD may also present with vertigo, and especially in patients with recurrent and prolonged vertigo attacks, CD should also be ruled out.

Keywords: Celiac Disease; Gluten; Vertigo
\end{abstract}

C eliac disease $(C D)$, intolerance to gluten, is characterized by the autoimmune inflammation of the small intestine in genetically susceptible individuals. Because of the diverse clinical presentations and extraintestinal symptoms, it is not always easy to diagnose CD. Unfortunately, if undiagnosed, severe complications that would be preventable with gluten-free diet may occur in the course of the disease. ${ }^{[1]}$ Undiagnosed CD can lead to many complications, such as malnutrition, osteoporosis, and neurologic complaints. ${ }^{[2]}$ Herein, we will report a case of a patient diagnosed with $C D$ during investigations performed for recurrent vertigo attacks.

\section{Case Report}

A 31-year-old female patient with prolonged vertigo was admitted to the otorhinolaryngology department. She was under follow-up of otorhinolaryngology for 2 years due to the recurrent vertigo attacks. These attacks were continuing for about 3-4 weeks and affecting the daily life of the patient. For the last 2 years, she had six attacks. For this attack, the otorhinolaryngology department prescribed methylprednisolone; however, because of the gastrointestinal symptoms of the patient, such as heartburn, nausea, and stomachache, they consulted the patient with the gastroenterology department. Her gastrointestinal symptoms were also not new, and the stomachache was preventing the patient from sleeping at nights. Upper gastrointestinal endoscopy was performed, which revealed patchy edematous changes with millimetric ulcers and comblike appearance on villi in the proximal duodenum. Biopsy was obtained and revealed lymphocytic infiltration of the duodenal mucosa with a marked villous atrophy (Marsh $3 b$ ). Then, her serological tests (tissue transglutaminase $\lg \mathrm{A}$ and

Cite this article as: Kasapoglu B, Yozgat A, Kekilli M. An Unusual Presentation of Celiac Disease: Vertigo. Lokman Hekim Health Sci 2021; 1(1):32-33.

Correspondence: Ahmet Yozgat, M.D. Ufuk Universitesi Tip Fakultesi, Ic Hastaliklari Anabilim Dali, Gastroenteroloji Bilim Dali, Ankara, Turkey

E-mail: a_yozgat@yahoo.com Submitted: 18.07.2021 Accepted:31.07.2021

Copyright 2021 Lokman Hekim Health Sciences

OPEN ACCESS This is an open access article under the CC BY-NC license (http://creativecommons.org/licenses/by-nc/4.0/) 
$\lg G$ and anti-endomysial $\lg A$ and $\lg G$ ) were obtained and were highly positive. The patient was diagnosed with $C D$, and with gluten-free diet, she did not have any vertigo or dizziness attacks for two years.

\section{Discussion}

Vertigo is a nonspecific and common neurologic sign necessitating a cautious diagnostic study on a wide spectrum of diseases including the central nervous system and systemic and metabolic chronic disease. However, to the best of our knowledge, there is only one case on the association of $C D$ with vertigo and nystagmus reported in literature, which is in an 11-year-old girl. Similar with our case, in that report, vertigo also disappeared on the third month of gluten-free diet. ${ }^{[3]}$

Vertigo, if not appropriately treated, may disturb life quality. On the other hand, undiagnosed or untreated CD may also cause many health problems, such as malnutrition, vitamin deficiencies, and neurologic complaints. Although the most common symptoms of $C D$ are gastrointestinal symptoms, such as diarrhea, abdominal pain, and bloating, CD may also manifest with extraintestinal symptoms. ${ }^{[2]}$ In a recent review, ear-nose-throat manifestations of $C D$ were analyzed, and sensorineural hearing loss, obstructive sleep apnea, nasal septal perforation, epistaxis, and vertigo with nystagmus were reported to be associated with immunologically mediated mechanisms. ${ }^{[4]}$
In conclusion, clinicians should be aware that $C D$ may also present with vertigo, and especially in patients with recurrent and prolonged vertigo attacks, CD should also be ruled out.

Peer-review: Externally peer-reviewed.

Informed Consent: Written informed consent was obtained from patients who participated in this study.

Authorship Contributions: Concept: AY, BK; Design: AY, BK; Supervision: AY, BK, MK; Data Collection or Processing: AY, BK; Analysis or Interpretation: AY, BK; Literature Search: AY, BK; Writing: AY, BK; Critical Review: AY, BK, MK.

Conflict of Interest: None declared.

Financial Disclosure: The authors declared that this study received no financial support.

\section{References}

1. Laurikka P, Nurminen S, Kivelä L, Kurppa K. Extraintestinal manifestations of celiac disease: early detection for better long-term outcomes. Nutrients 2018;10(8):1015.

2. Lundin KE, Kelly CP, Sanders DS, Chen K, Kayaniyil S, Wang S, et al. Understanding celiac disease monitoring patterns and outcomes after diagnosis: A multinational, retrospective chart review study. World J Gastroenterol 2021;27(20):2603-14.

3. Mohn A, di Ricco L, Magnelli A, Chiarelli F. Celiac disease-associated vertigo and nystagmus. J Pediatr Gastroenterol Nutr 2002;34(3):317-8.

4. Karunaratne D, Karunaratne N. ENT manifestations of celiac disease: a scholarly review. Ear Nose Throat J 2020 Nov 6 [Epub ahead of print], doi: 10.1177/0145561320972604. 